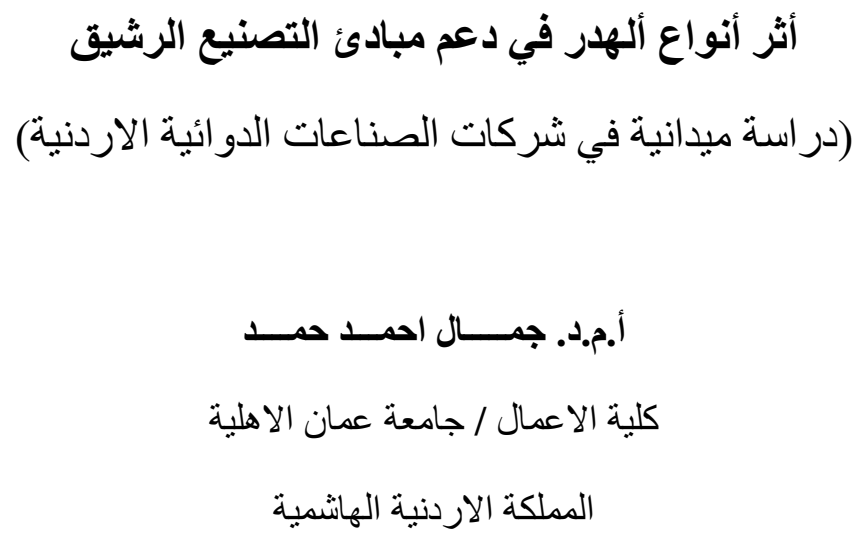

الملخص:

في السنوات القلبلة الماضية تز ايدت اهمية التصنيع الرشيق، لذلك فان العديد من الثركات الصناعبة نولي اهتماما

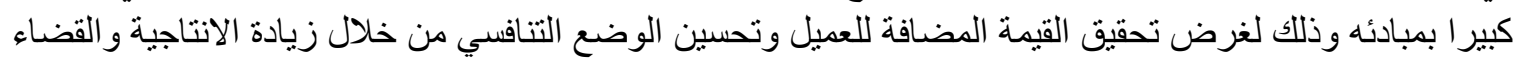

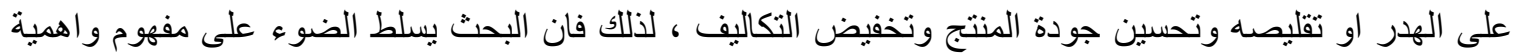
العمليات الرشيقة واهم مبادئها و على الهدر بأنو اعه وكيفية القضاء عليه .

ومن هذا المنطلق يسعى البحث الى تحديد اثر الهدر على المبادئ الاساسية للتصنيع الرشيق في شركات الصناعات

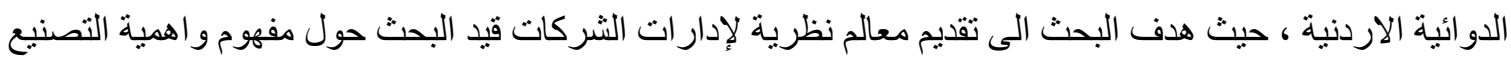
الرشيق ومبادئه ومدى ناثير الهدر عليه ليتسنى لتللك الثركات الحد من الهدر وصو لا للتصنيع الرشيق. للإن.

بوخته:

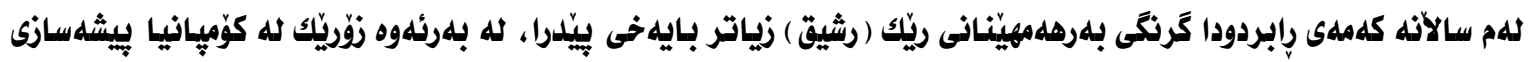

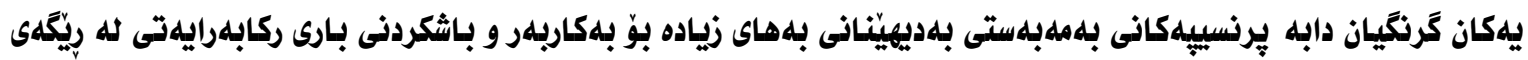

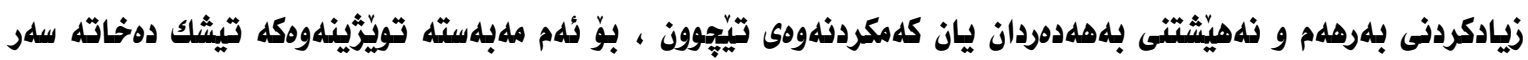

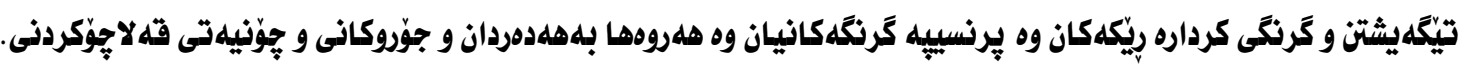

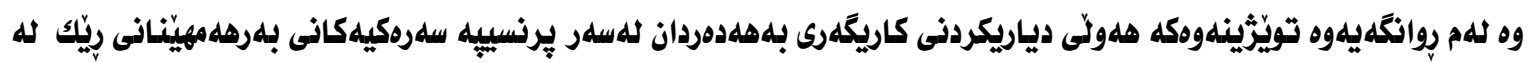

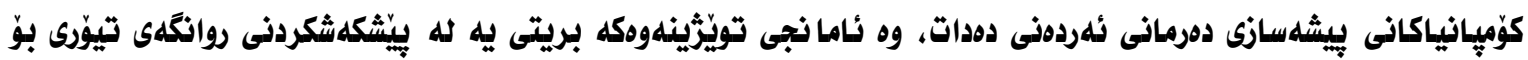

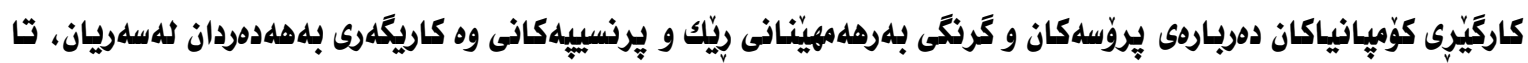

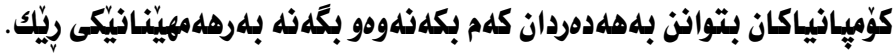




\begin{abstract}
:
In the last few years, the importance of lean manufacturing has increased, so many industrial companies are paying great attention to their principles in order to achieve the customer added value and improve the competitive position by increasing productivity, eliminating waste or reducing it; increasing quality and reducing costs. So the research will shed some light on the concept and importance of lean manufacturing and its basic principles especially the waste and how to eliminate it.

The research main objective is to determine the effect of waste on the basic principles of the leanmanufacturing in the Jordanian pharmaceutical companies. The aim of the research is to provide theoretical features for the companies under discussion about the concept and importance of lean manufacturing and their impact on waste to achieve the lean manufacturing.
\end{abstract}




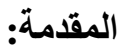

أن التصنيع الرشيق كنظام متكامل يستخدم جميع الإمكانيات المتوفرة و المتمثلة بالتقتنات والأدو ات و الامكانيات المالية

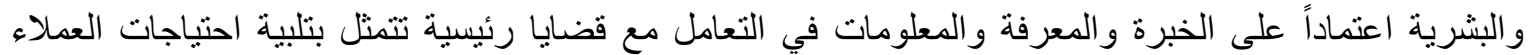

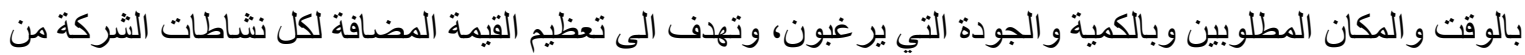

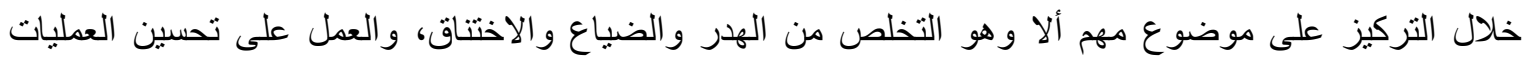

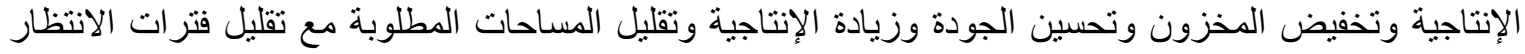
والسعي لإقامة علاقات متميزة مع المجهزين وزيادة الطاقة الإنتاجية واستخدام أفضل الموارد البشات البرية.

ولكي تتحقق أهداف التصنيع الرشيق فلا بد من تحقيق مجموعة من المبادئ التي بوجودها ترتقي الثركات العاملة بهنيا

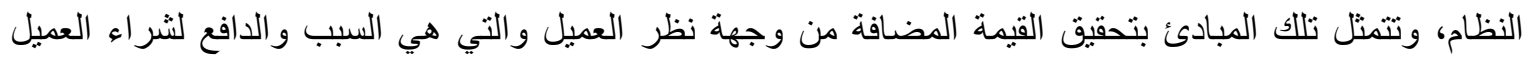

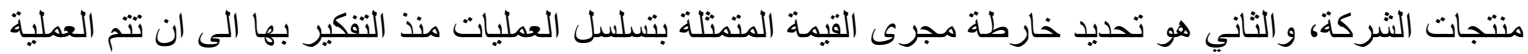

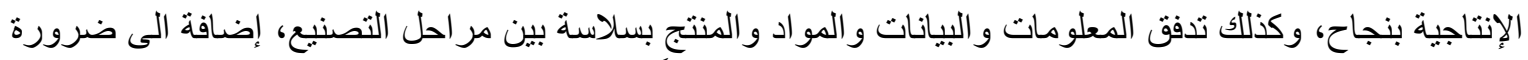

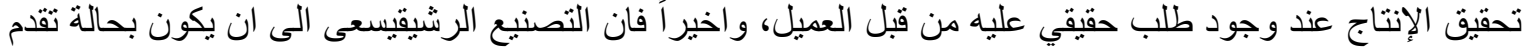

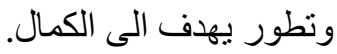

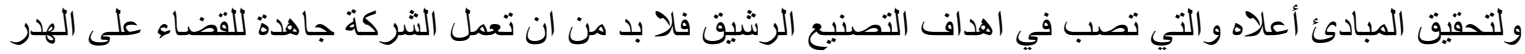

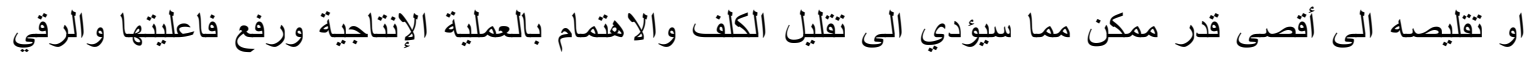

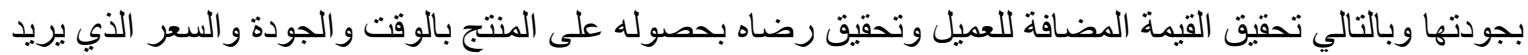

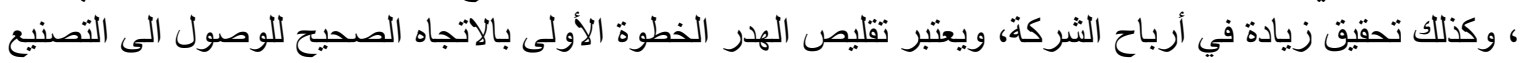

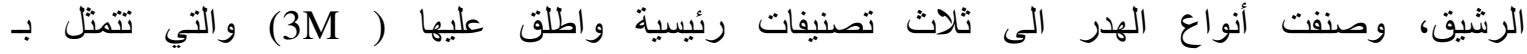
(Muda,Muri,Mura)

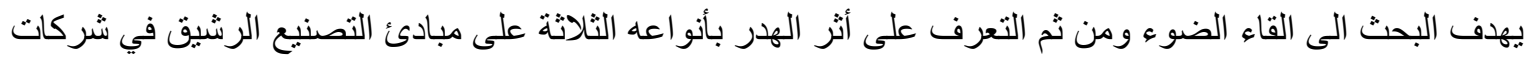

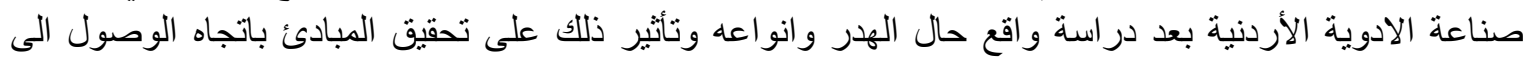

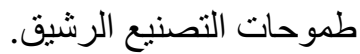

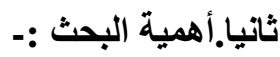 \\ تكمن أهمية البحث في النقاط الآتية:-}

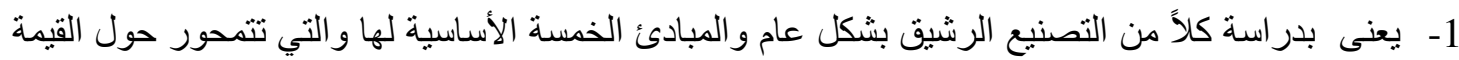

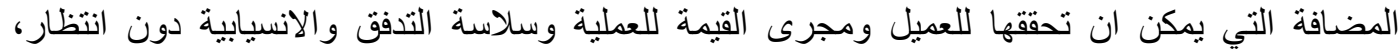

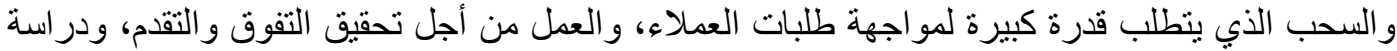

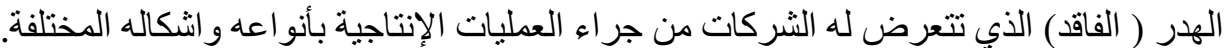

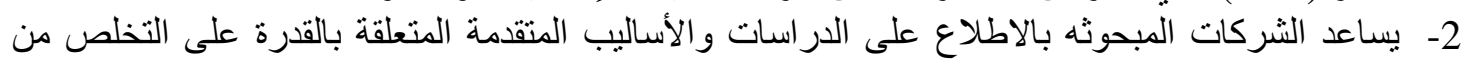

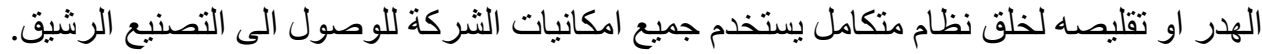

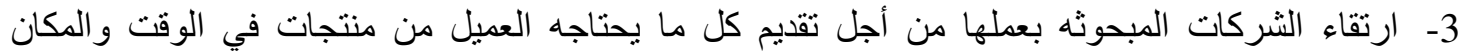

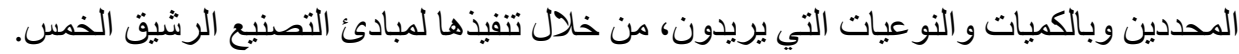

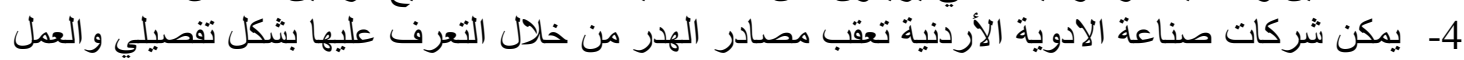

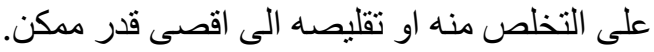
5- اذا ما استطاعت الثركات المبحوثة ان تحقق ما ورد في في أعلاه فأنها بالتأكيد ستكون قادرة على تحقيق القدرة التنافسية مع مثيلاتها من الثركات الصناعية في حقل الادوية. 
6- قد يكون لهذا البحث دوراً في دفع الشركات المبحوثة للعمل بجدية للتخلص من الهدر او تقليصه وصو لاً الى الى

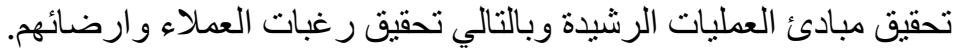

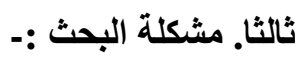

تتمثل مشكلة البحث في التعرف على قدرة شركات الصناعات الدو ائية الأردنية في تحديد أنواع الهدر و إمكانية القضاء

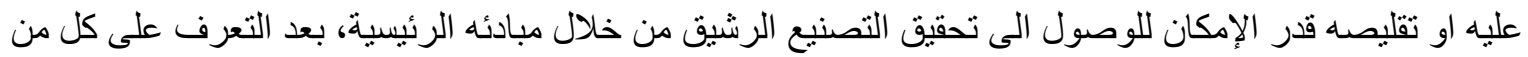

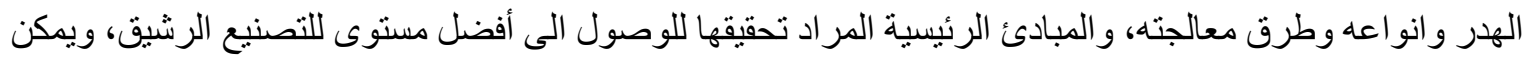

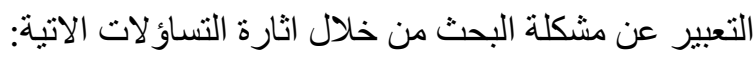

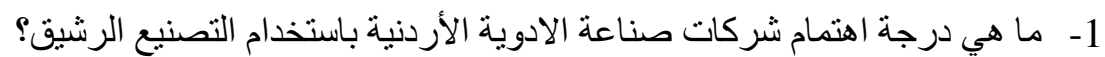

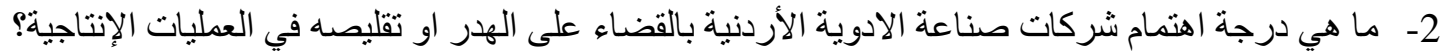

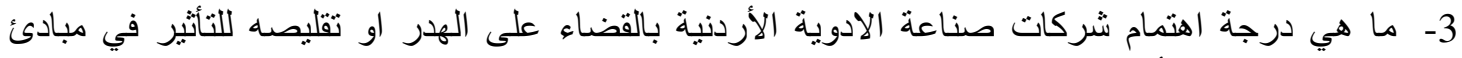

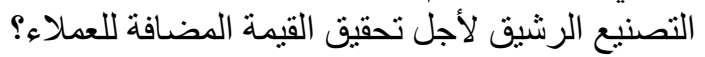
4- هل يوجد اثر بين القضاء على الهدر بأنو اعه او تقليصهاه ومبادئ التصنيعالرشيق في الثركات المبحوثة.

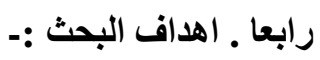
يهدف البحث الى بلوغ عدة ابعاد تتمثل بالآتي:1- تقديم اطار نظري للتصنيع الرشيق عبر تطوره التاريخي ومفهومه وأهميته ومبادئه الخمسة، إضافة الى الهدر و أنو اعه. 2- تحديد مدى تأثثير الهُر بأنواعه الثلاثة على المبادئ الرئيسية للتصنيع الرشيق في الثركات المبحوثة.

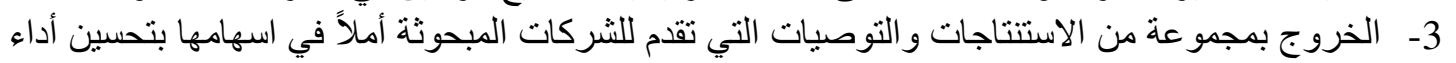
تللك الثركات وتحفيز ها نحو تعزيز تطبيق التصنيع الرشيق.

\section{المبحث الاول}

الجاتب النظري

المطلب الاول : التصنيع الرشيق

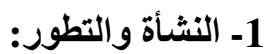

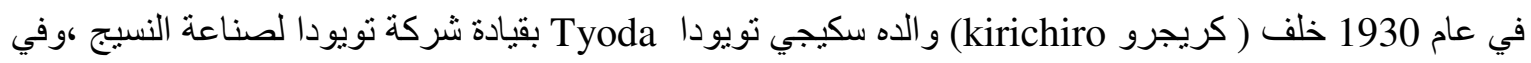

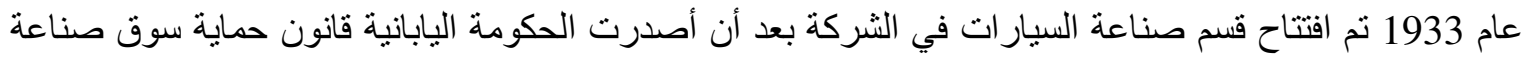

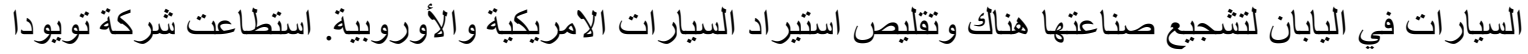

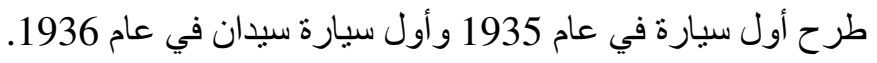

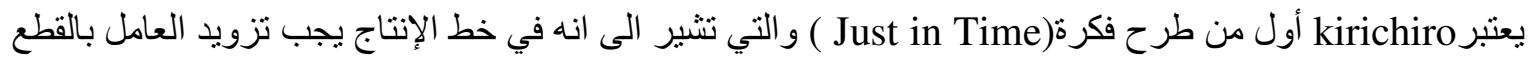

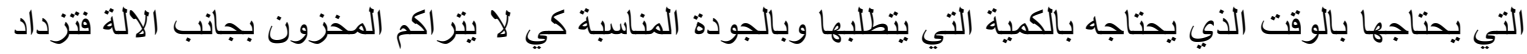

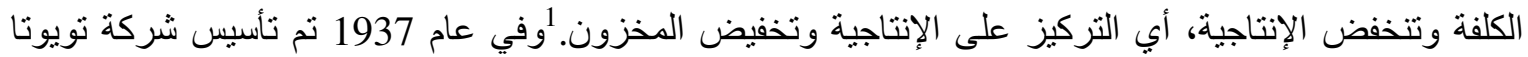
(Toyota) في السوق اليابانية، وفي عام 1950 وبعد انتهاء الحرب العالمية الثانية وبسبب المشاكل العمالية استقال كريجرو وحل

1- Heizer.J,Render.Band Munson.c , “ Opertions Management Sustainability and supply Chain Management" 12th edition,2015,P 638 
محله ابن عمه ايجيك تويودا و الذي اشتهر بتطبيق مبدأ (Takt Time)الذي يقوم بخلق ردم بين معدل الطلب والقدرة الإنتاجية ويتم الاحتساب لوقت الـ (Takt) بقسمة السعر على الطلب.

كان من ضمن فريق تويودا مهنس يدعى(Taichii Ohno) والذي ساهم في صقل مبادئ تويوتا للتصنيع (TPS) الذي يعتبر حجر الزاوية للتصنيع الرشيق حيث قام بزيارة مصانع في أوروبا (Toyota Production System)

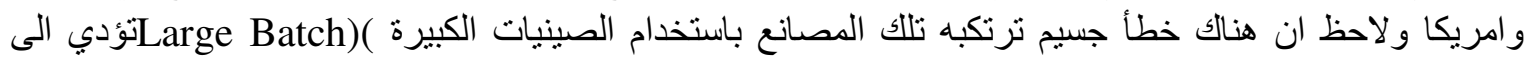

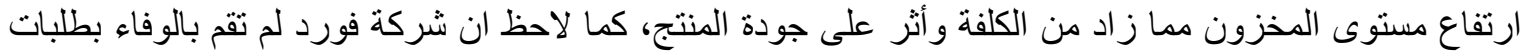

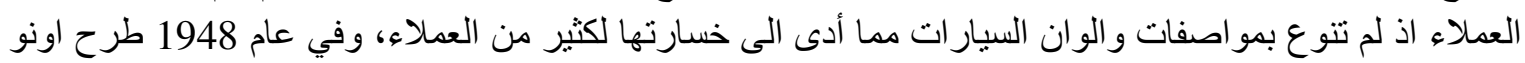

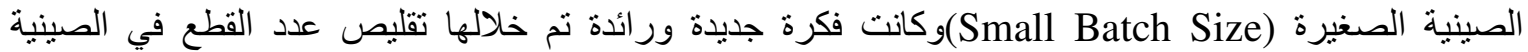

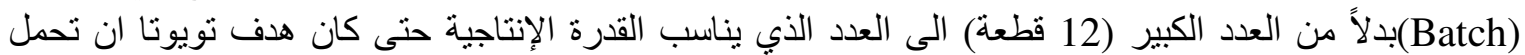

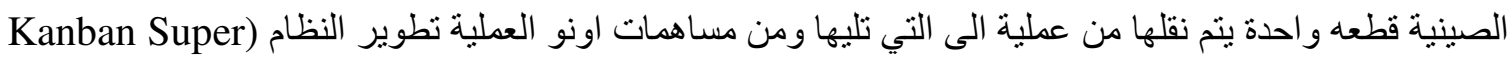

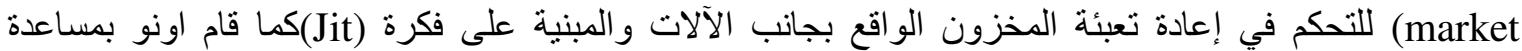

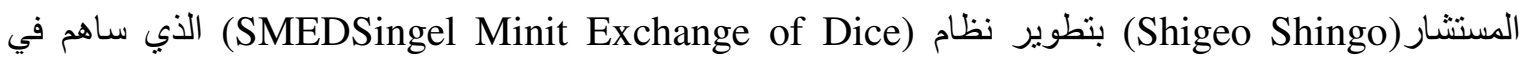

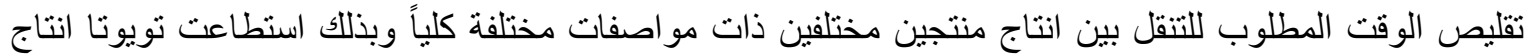
سيار ات ذات مواصفات مختلفة في وقت متغير مقارنة بنظريتها في أوروبا وامريكا.

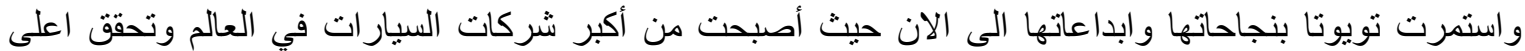

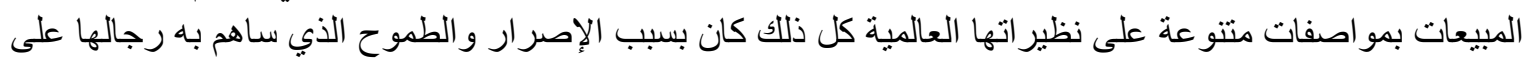
مر التاريخ وييقى طموحها ان تستمر بذلك.

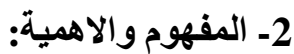

وردت مفاهيم عدة للتصنيع الرشيق في ادبيات إدارة الإنتاج و العمليات فنهم من برى فيه بأنه انتاج يركز على إزالة جميع مظاهر الهلر و الانحر اف و التي لا تضيف قيمة للمنتج النهائي.

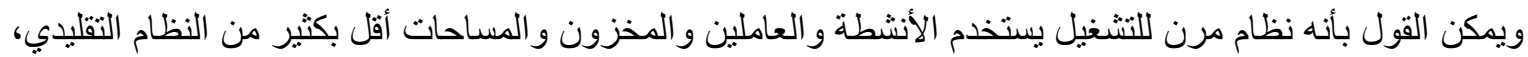

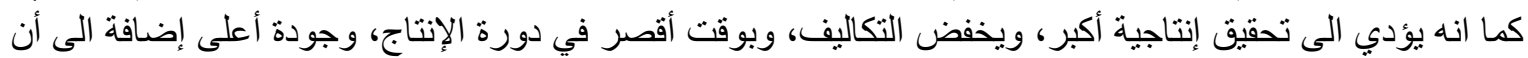

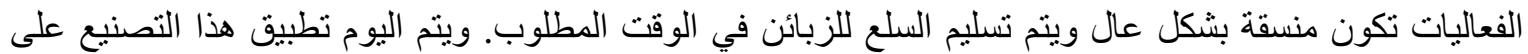

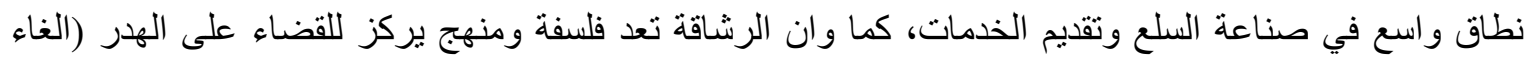

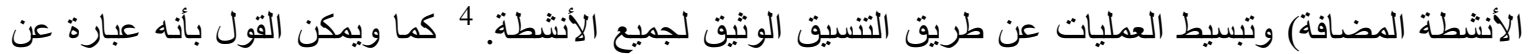

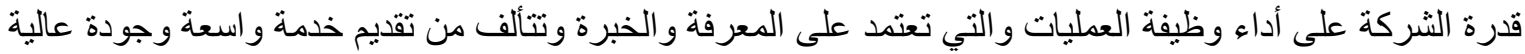
وتسليم سريع وكلفة منخفضة وبالتالي مساعدة الثركة في خلق الميزة التنافسية المستدامة. 5

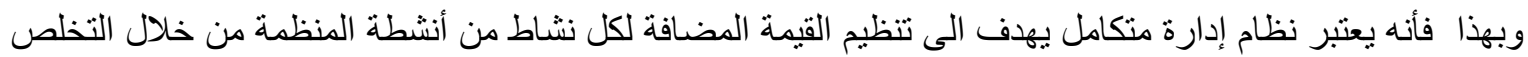

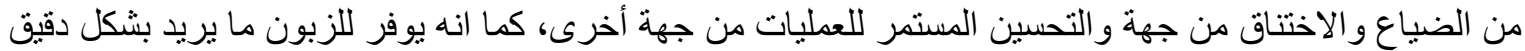

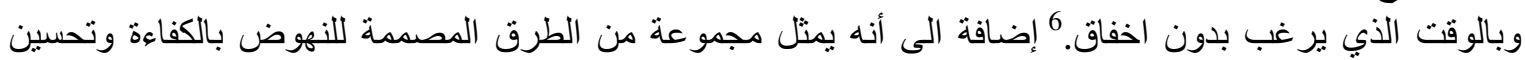
6حسن ، عبد الكريم و النجار ، صباح ، " إدارة الإنتاج و العطليات"، ط4 ، الذاكرة للنشر و التوزيع، 2012، ص460 


\section{The Scientific Journal of Cihan University - Sulaimanyia ISSN 2520-7377 (Online), ISSN 2520-5102 (Print)}

DOI : http://dx.doi.org/10.25098/1.3.1
Vol. (1) Issue (3)

PP: 03-22

May/2017

الجودة للمنتج، 7و هذا يعني ان التصنيع الرشيق يتعامل مع قضايا رئيسية تعد المبادئ الرئيسية له و التي تتمثل

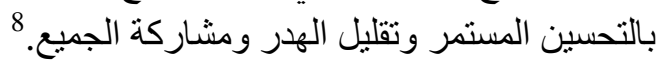

اذاً فأن التصنيع الرشيق يحقق العديد من الفوائد التي تتمثل بتزويد العملاء بما يريدون وتحقيق رغباتهم من خلال

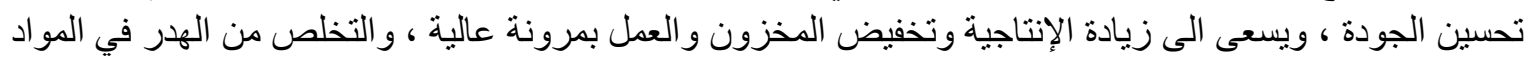

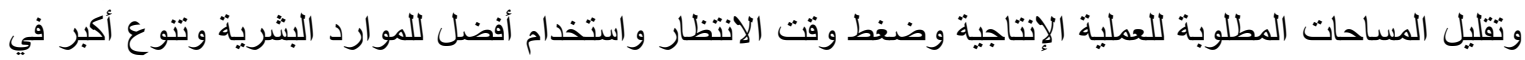
المنتجات و العمل على توطيد العلاقة مع المجهزين

3-مبادئ التصنيع الرشيق

هناك مجمو عة من مبادئ التصنيع الرشيق و التي تندرج تحت المسميات الخمسة التالية:_10

1- تحديد القيمة المضافة من وجهة نظر العميل ( Customers Value) وتعني تحقيق هدف العميل من جراء

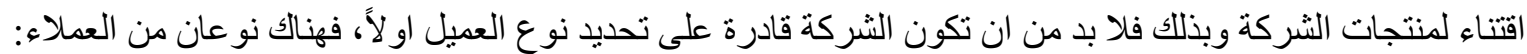

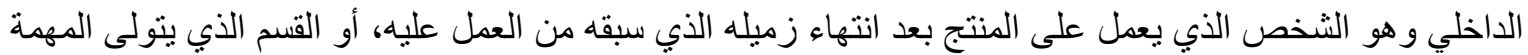
بعد انتهاء قسم سابق منه، أو الثركة التي تحتاج للمنتج كمادة أولية أو نصف مصنعة لأل التستخدامه في عملية إنتاجية

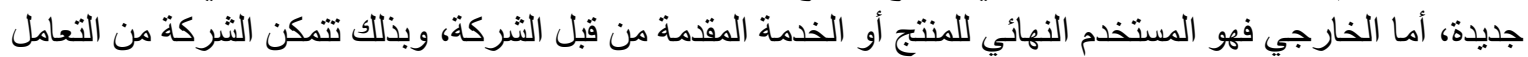

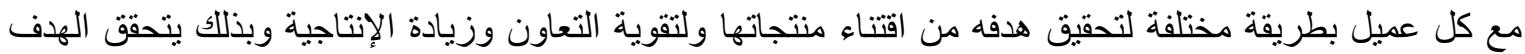

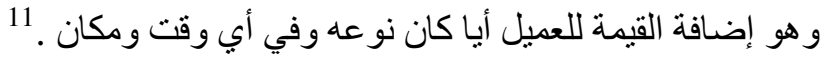

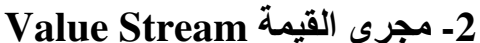

سلسلة العمليات التي تبدأ بفكرة ومن ثم تنفيذ تلك الفكرة لتمتد مجرى القيمة من استلام المواد الأولية عبر سلسلة

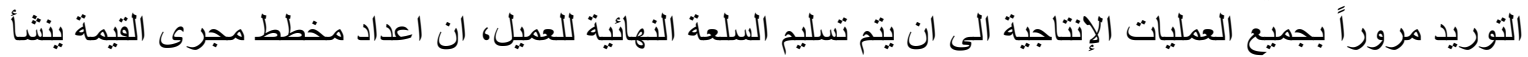

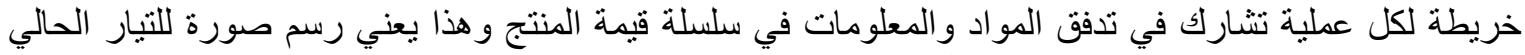

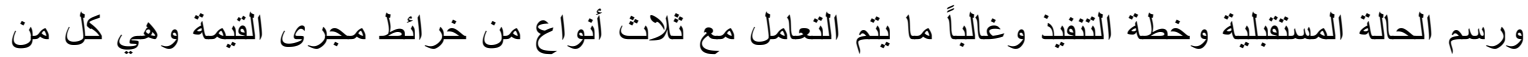

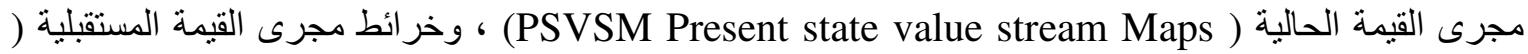

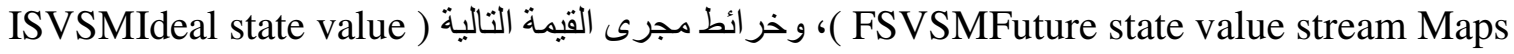

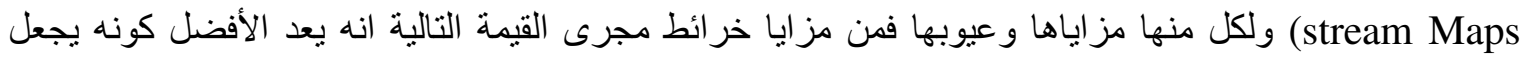
الثركة تفكر في كيفية التخلص من الهدر والذي يحقق أفضل قيمة مضافة و اقصر وقت مدكن، ولكن بذات الوقت فيات فانه

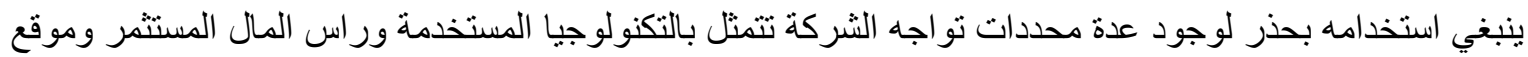

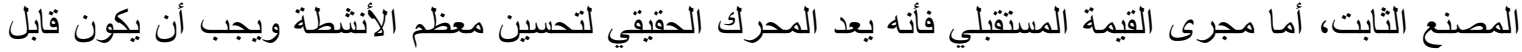
للتحقيق وليس مثالياً ويكون لفترة زمنية معقولة تتر اوح بين 3-6 شهور كي تكون مكتملة كما تم رسمها ويتم اعدادها

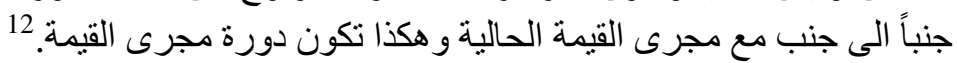

كل عائلة لمنتج معين هي مجرى قيمة وقد يتلاقى أكثر من مجرى للقيمة في مرحلة معينة من مر احل سلسلة العمليات وتسمى هذه النقطة ( The capleng Poient ) ، فلا بد من الحرص هل على كلى كل مجرى على على حدة و التعامل معه منفرداً

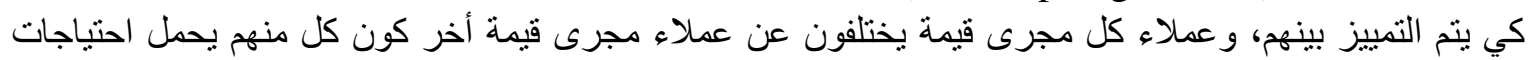
خاصة ورغبات مختلفة ويتطلب حلول مختلفة مع كل على حدة لذلك لا بد من فهم احتياجات كل عميل لكي يتم خدمته بفاعلية وذكاء.

${ }^{7}$ Buggy,J \& Nelson.J, Applying Lean production in Mealthcare Facilities, http://www.Informedesing.

Umn.edut news,2005. Pdfm p:1

${ }^{8}$ Slack . N . \& others, “Operations Management," $4^{\text {th }}$ edition, prentice- Hell, 2004, p:524

${ }^{9}$ Heizer J.\& , p: 638

${ }^{10}$ Gopalakrishanan. N. ." Simplified Lean manufacture elements, Rules, tools, and implementation, New

Delhi , 2010, p:41

${ }^{11}$ Gopalakrishanan, N, P:42

${ }^{12}$ Lonnie Wilson, "How to implement lean Manufacturing, 2010, Mc Graw-Hill , p:111 


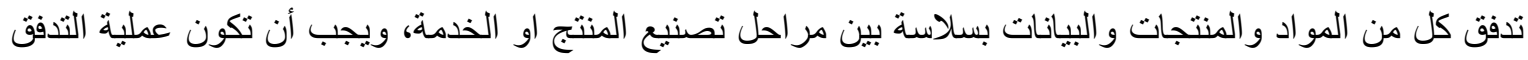

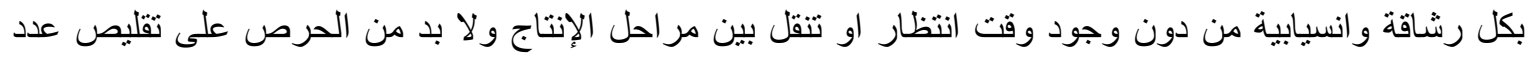
القطع في الصينية ( Batch) او في الدفعة ليتناسب مع القدرة الإنتاجية والطلب و وعندها ستحقق السلاسة في التدفق،

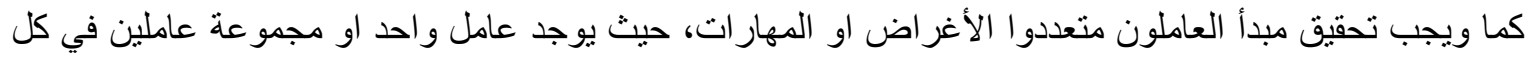

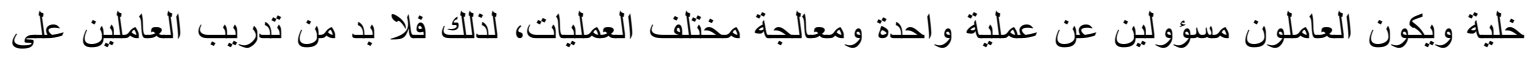

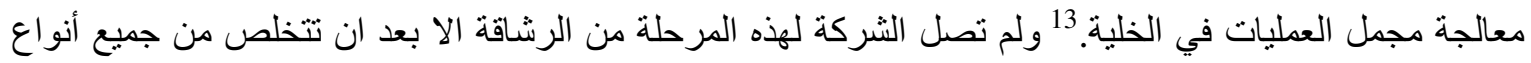
الهدر كي تمكن القيمة المضافة من السير بشكل سلس دون اية عقبات.

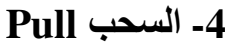

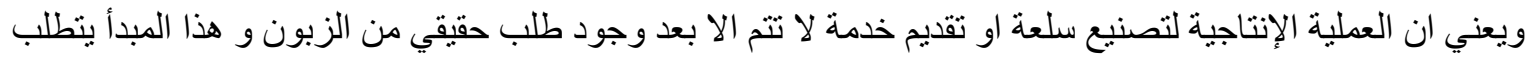

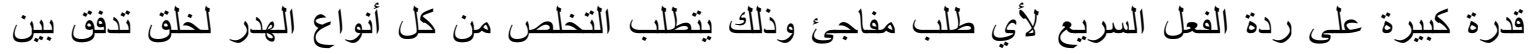
العمليات، ويعد هذا المبدأ كأداة قياسية للرشاقة لالي في النظام الإنتاجي 14

على عكس ما تستخدمه أنظمة MRR لمبدأ الدفع لتدفق العمل و الذي بموجبه يتم العمل بالإنتاج وفقاً للجدولة قبل

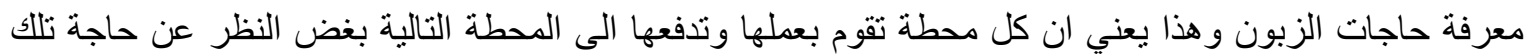

المحطة الى تلك الاعمال من عدمها، مما يؤدي الى ضرون الى بورة الاحتفاظ بمستويات عالية من المخزون بين المحطات. 15

بالتالي فأن مبدأ السحب يعني ان العمل عند وصول الطلب على المنتج وحينها تبدأ العملية الإنتاجية او الخدمية

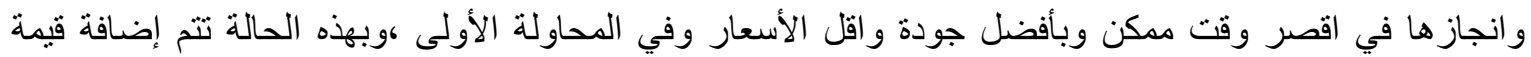
للعميل وبنفس الوقت تتمكن الشركة من تقليص كل أنو اع المخزون و ولتمد تر اكمها بين محطات العمل ،وستكون سلسلة

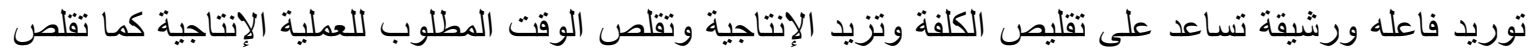

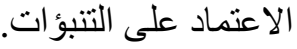

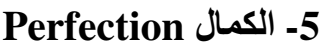

يظل التصنيع الرشيقينر للكمال كمرك أساسي ويظل مهووسا فيه، ولذلك بسعى دائماً لتحقيق ما يسمى اخر نسخة

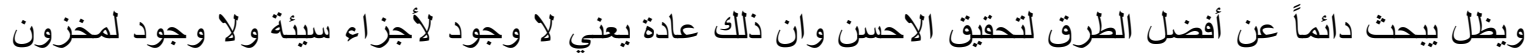

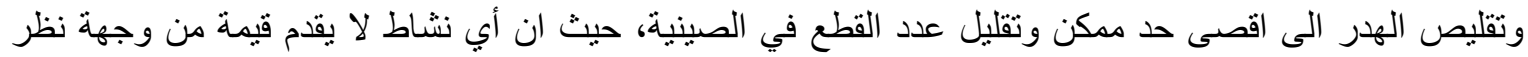
العميل فانه هدر كون العميل هو الذي يحدد قيمة المنتج كونه من سيدفع ثمنه في النهاية. 16

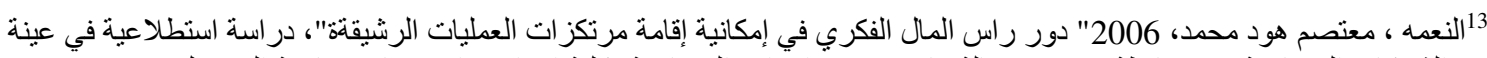

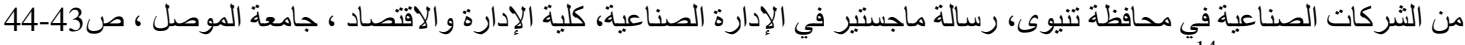

${ }^{15}$ Krajewski. L.j, Ritzam.L.P,andMolhotra.M.K,"operations management processes and supply chains," $10^{\text {th }}$ edition,2013,p;307-320

${ }^{16}$ Heizer, J p:638 


$$
\text { المطلب الثاني: الهار ( الفاقد): }
$$

يعمل التصنيع الرشيق في شركة تويوتا على تقليص الهدر مع زيادة القيمة المضافة للمنتج او الخدمة سعياً منه

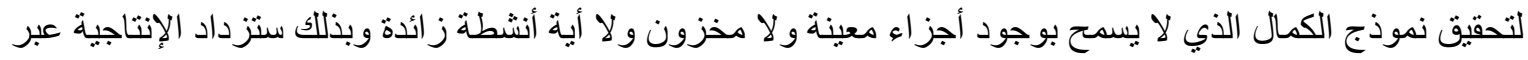

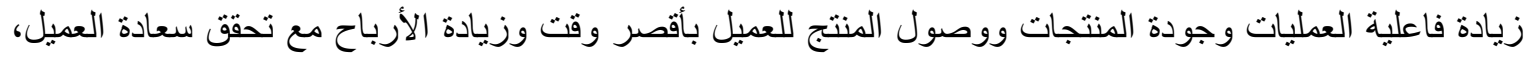

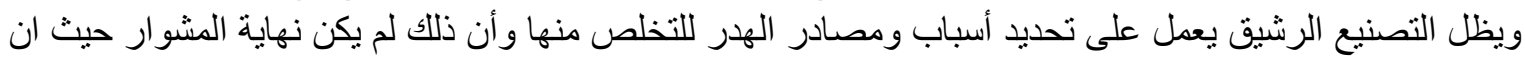

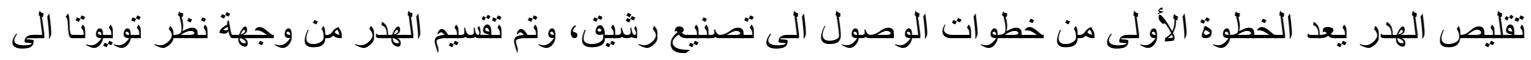
3 مصادر رئيسية اطلق عليه (3M) وكما ياتي:-

Waste...Muda

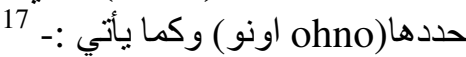
Overproduction -a

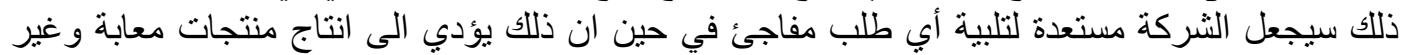
مطابقة لاحتباجات العميل إضافة الى زيادة مفرطة في منسوب المخزون مما يؤدي الى الى زيادة الكلفة وخفض

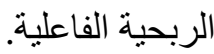

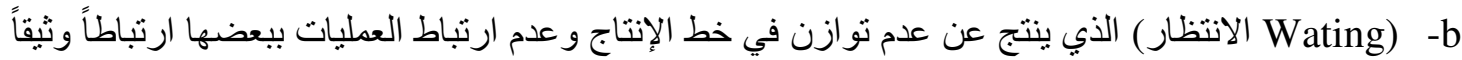

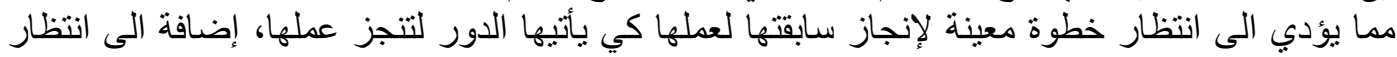

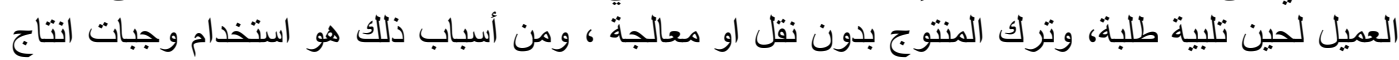

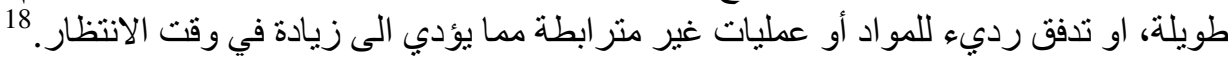

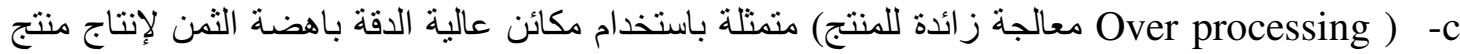

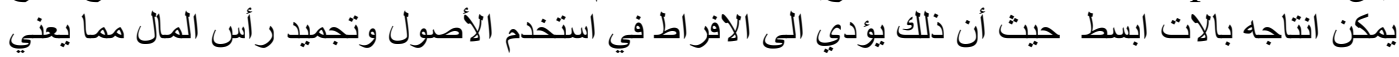

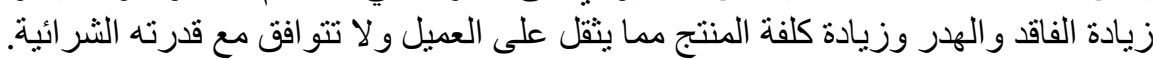

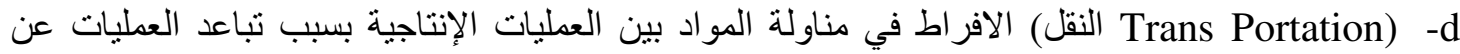
بعضها وترتييها غير المدروس مما يؤدي الى الحاق الضرر بالمناد بلنجات وزيادة الهدر فيها وزيادة الكلفة دون

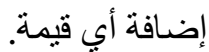
Unnecessary Motion) -e

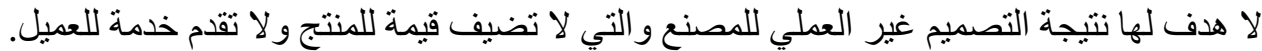
Unnecessary inventory) - -f من النقد مما يقلل من فرص استثمار هذه المبالغ في مشاريع أخرى كما ويتطلب ذللك مساحة إضافية وتكاليف

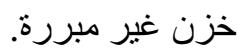

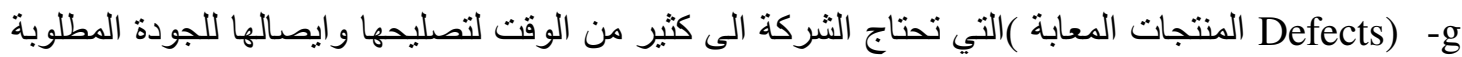

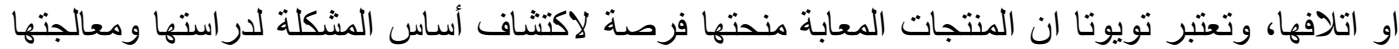
ل التماشيها مستقبلاً.

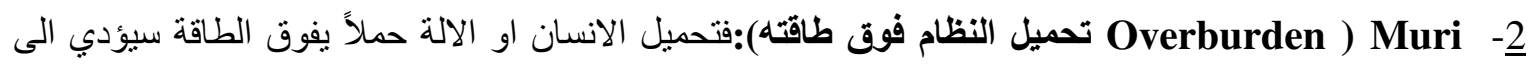

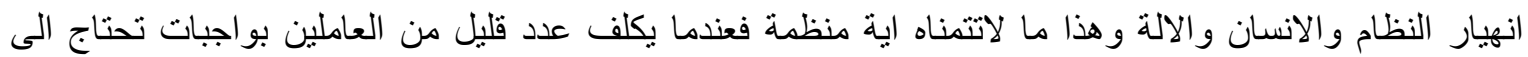

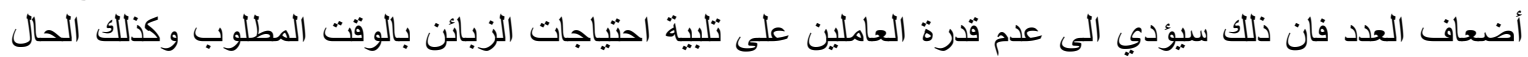
ينعكس اذا ما تم تحميل أجزاء النظام اكثر من طاقتها فان ذلك سيؤدي الى ضياع لئاعات كثيرة.

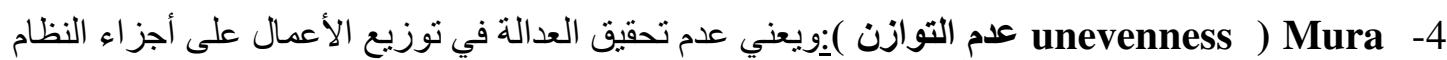

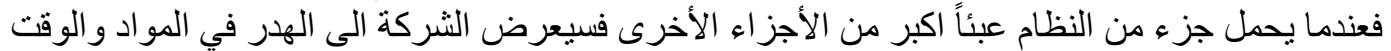

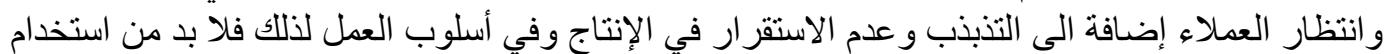

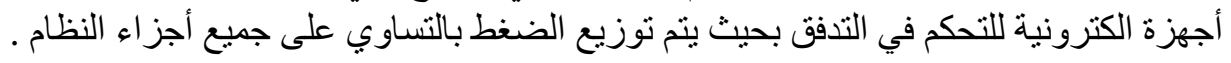

\footnotetext{
${ }^{17}$ Heizer.J, p:638

${ }^{18}$ Krajewski. J , p:297
} 


$$
\text { إضافة لما تقدم فأن هناك أنواع أخرى من الهدر يمكن تلخيصها بما يأتي: }
$$

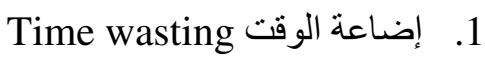

2. 3.

4he wast of inappropriate systems الأنظمة غير الملائمة

5e wast of Energy and water اهدار الماء و الطاقة الطيرة

6he wast of Knowledge المدار المعرفة

$$
\text { المبحث الثاني }
$$

المطلب الاول: انموذج الدراسة

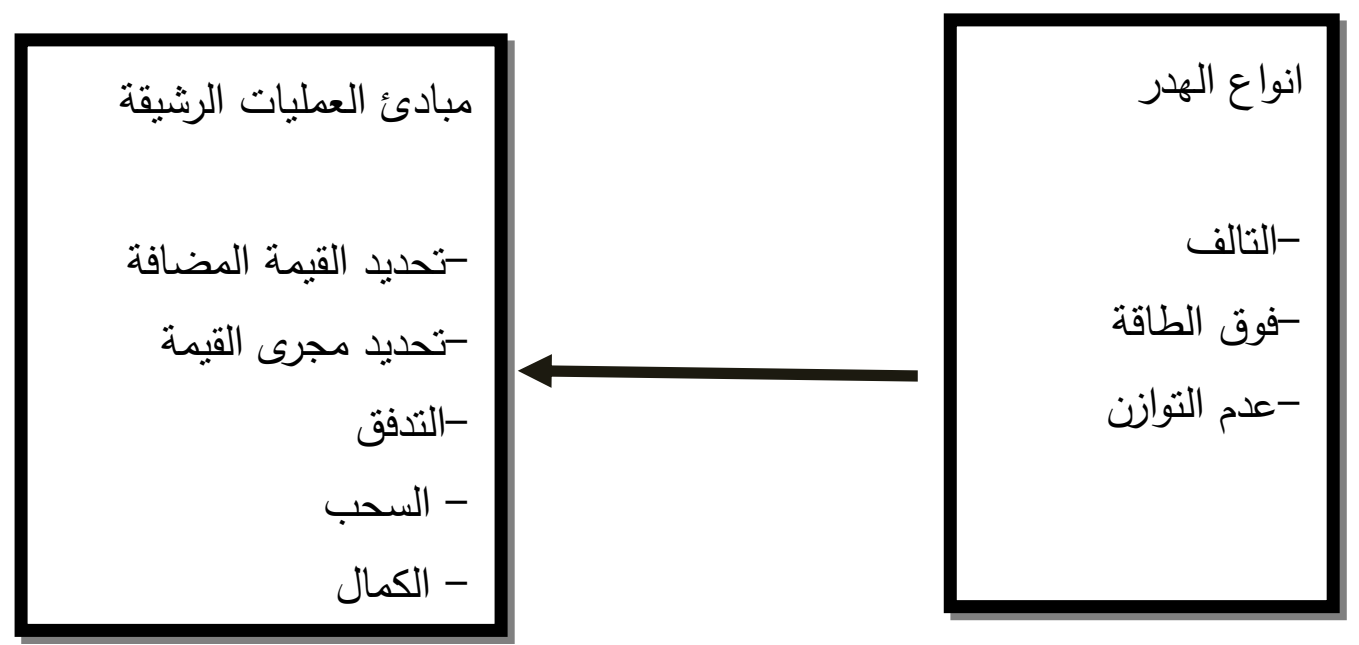

$$
\text { شكل (1) انموذج الدر اسة }
$$

المطلب الثاني : مجتمع الاراسة ووحدة المعاينة:

تكو نمجتمعالبحث منجميعشر كاتالأدويةالأردنيةلعام 2015 والبالغعددها (13) شركة أما العينة فتمثلت في الادارة العليا

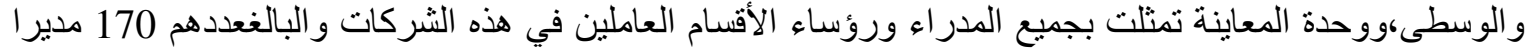

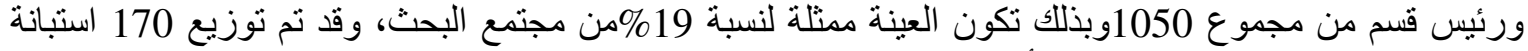
و استردادئ120 استبانة صنالحة للتحليل أي ما نسبته 70\% من الاينة 
جدول (1) شركات صناعات الادوية الاردنية

\begin{tabular}{|c|c|c|}
\hline سنة التأسيس & 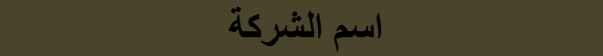 & الرقم \\
\hline 1957 & 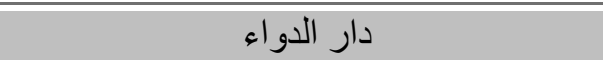 & 1 \\
\hline 1962 & الشركة العربية لصناعة الأدوية & 2 \\
\hline 1977 & شركة أدوية الحكمة & 3 \\
\hline 1978 & الثركة الأردنية لإنتاج الأدوية & 4 \\
\hline 1983 & المركز العربي للصناعات الدو ائية و الكيميائية & 5 \\
\hline 1989 & الثركة المتحدة لصناعة الأدوية & 6 \\
\hline 1993 & شركة الحياة للصناعات الدو ائية & 7 \\
\hline 1993 & شركة فيلادلفيا للصناعات الدوائية & 8 \\
\hline 1993 & الشرق الاوسط للصناعات الدو ائية & 9 \\
\hline 1994 & الثركة الدولية للدو اء & 10 \\
\hline 1996 & الاردنية السويدية للمنتجات الطبية & 11 \\
\hline 1997 & الكيندي للصناعات الدو ائية & 12 \\
\hline 1999 & نهر الأردن للصناعات الدوائية & 13 \\
\hline
\end{tabular}

المطلب الثالث ـاختبار صدق أداة الدراسة وثباتها:

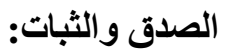

استخدم الباحث الاستبانة كأداة للار اسة وتم اختبار صدق أداة الدراسة من خلال اتباع منهج الصدق الظاهري، وذللك

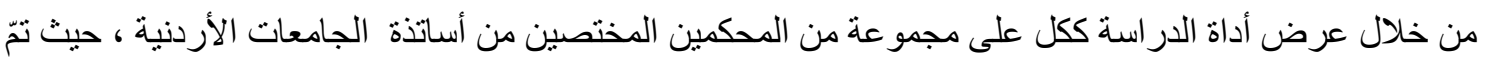
تحكيمها من قبلهم بمنهجية علمية. 
ولاختبار الثبات، قام الباحث باستخدام اختبار كرو نباخ ألفا Cronbach’s Alpha) لقياس مدى ثبات أداة القياس

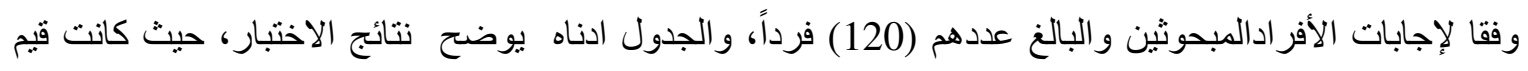
كرو نباخ ألفا لجميع متغيرات الدر اسة وللأداة ككل مقبولة في البحوث و الدر اسات الإنسانية. جدول (2) نتائج اختبار معامل كرونباخ ألفا لقياس ثبات الاستبانة

\begin{tabular}{|c|c|c|c|}
\hline قيمة (a) ألفا & عدد الفقرات & البعد & انواع الهُر \\
\hline 0.786 & 4 & التالف & \\
\hline 0.803 & 4 & تحميل النظام فوق طاقته & \\
\hline 0.881 & 4 & عدم التوازن & \\
\hline 0.901 & 4 & تحديد القيمة المضافة & \multirow{5}{*}{ مبادئ التصنيع الرشيق } \\
\hline 0.899 & 4 & تحديد مجرى القيمة & \\
\hline 0.855 & 4 & التدفق & \\
\hline 0.788 & 4 & السحب & \\
\hline 0.931 & 4 & الكمال & \\
\hline 0.992 & 32 & & ة ككل \\
\hline
\end{tabular}

$$
\text { المطلب الرابع ـ فرضيات البحث: }
$$

يسعى البحث لاختبار الفرضيات الصفرية التالية: H01(لفرضية الرئيسة الأولى: لا يوجد أثر ذو دلالة إحصائية عند مستوى دلالة (

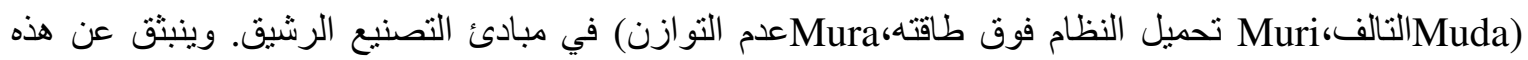
الفرضية الفرضيات الفرعية التالية: H01-1 الفرضية الفرعية الأولى: لا يوجد أثرذودلالة إحصائية عند مستوى دلالة) في مبادئ التصنيع الرشيق. (Muda )

H01-2 طاقته (Muri في مبادئ التصنيع الرشيق. H01-3 الفرضية الفرعية الثالثة: لا يوجد أثرذودلالة إحصائية عند مستوى دلالة) (Mura 


$$
\text { المطلب الخامس ـ عرض البيانات واختبار الفرضيات : }
$$

لأغر اض التحليل وتحديد تقديرات استجابات المبحوثين، وبناءً على النتائج التي تم التوصل إليها تم الاعتماد

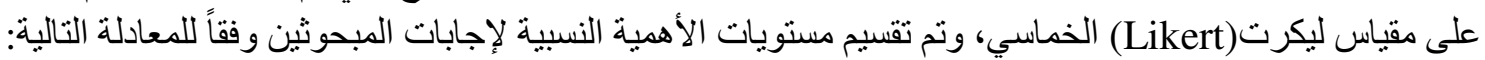
طول الفئة = (القيمة العليا للإجابةـ القيمة الدنيا للإجابة)/ عدد مستويات الأهمية الإنية

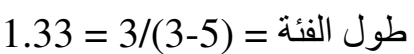
فيكون الحد الأدنى للمستوى المنخفض هو 13، ويمكن حساب الحد الأعلى للمستوى المنخفض كما يلي:

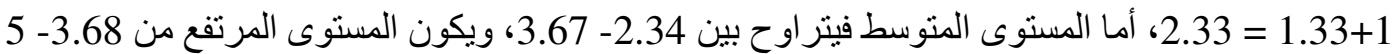

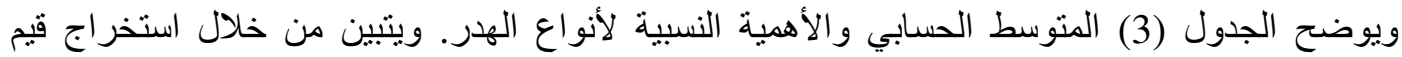

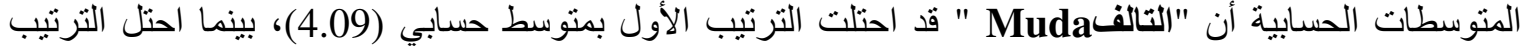
الأخير متغير "عدم التوازن Mura " بمتوسط حسابي (3.47) .

جدول (3) المتوسط الحسابي والأهمية النسبية لأنواع الهلر

\begin{tabular}{|c|c|c|}
\hline مستوى الأهمية النسبية & المتوسط الحسابي & المتغير \\
\hline منوسط & 3.47 & عدم التوازن عura \\
\hline مرتفع & 4.09 & التالف (الهُر)Muda \\
\hline مرتفع & 3.99 & Muriتحميل النظام فوق طاقته \\
\hline
\end{tabular}

Spss v16 المصدر: من اعداد الباحث بالاعتماد على مخرجات

المطلب السادس. تصورات المبحوثين حول مبادى التصنيع الرشيق:

يوضح الجدول (4) المتوسط الحسابي والأهمية النسبية لمتغير مبادئ التصنيع الرشيق. وتبين من خلال

استخر اج قيم المنوسطات الحسابية أن متغيرات مبادئ التصنيع الرشيق جاءت جميعها مرتفعة.

جدول (4) المتوسط الحسابي والأهمية النسبية لمبادئالتصنيع الرشيق

\begin{tabular}{|c|c|c|}
\hline مستوى الأهمية النسبية & المتوسط الحسابي & المتغير \\
\hline مرتفع & 3.88 & تحديد القيمة المضافة \\
\hline مرتفع & 3.81 & تحديد مجرى القيمة \\
\hline مرتفع & 3.99 & التدفق \\
\hline مرتفع & 3.96 & السحب \\
\hline مرتفع & 4.01 & الكمال \\
\hline
\end{tabular}

المطلب السابع. اختبار الفرضيات :

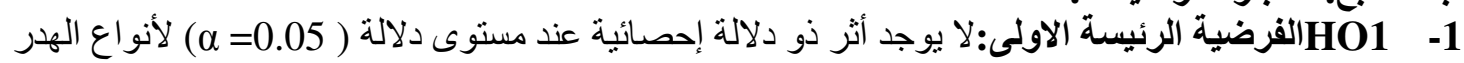

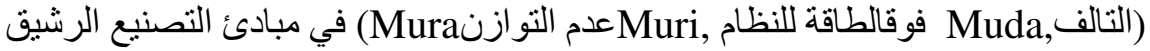




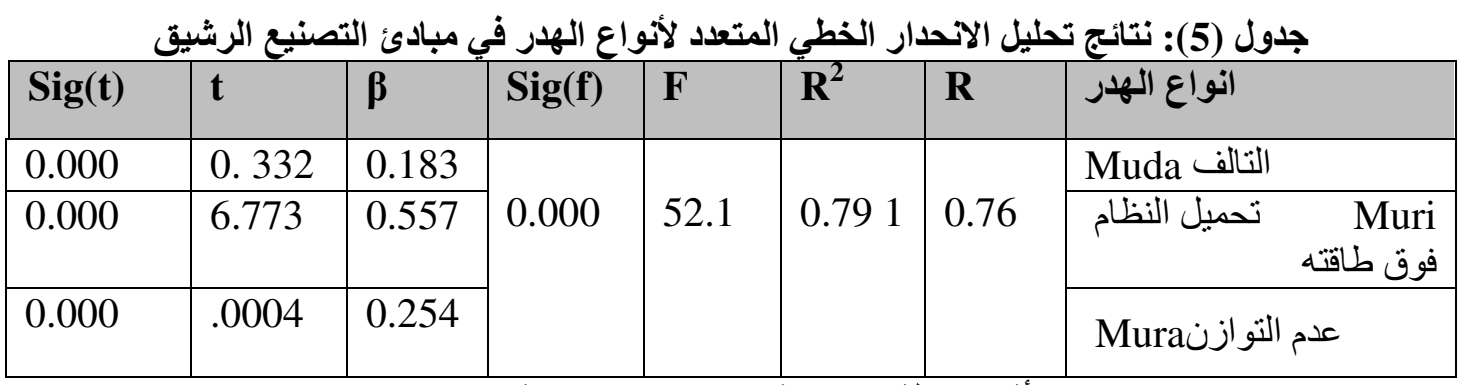

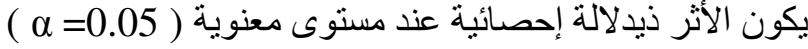

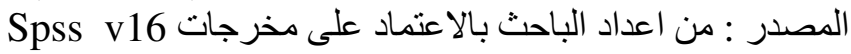

وقد بينت النتائج في الجدول (5)أن لأنو اع الهرر (التالف،تحميل النظام فوق طاقته،عدم التوازن)مجنمعة ذات تأثثر كبير في عناصر مبادئالتصنيع الرشيق؛ إذ كان التأثير دال من الناحية الإحصائية، وذلك لأن قيم مستويات الدلالة جميعهاو المر افقة لقيمة f البالغة (52.1) هي أقل من (0.05)، مما يعني وجود أثر لأنواع الهدر في مبادئ التصنيع الرشيق، وتفسر المتغيرات الأربعة ما نسبته (79.1\%) من تباين المتغير التابع.

ويظهر من الجدول (5) فيمة (t) المحسوبة لمتغير التالف (0.332) وبمستوى دلالة (0.000)ولمتغير فوق الطاقة (6.773) بمستوى دلالة (0.000) ولمتغير عدم التوازن (4.000) بمسنوى دلالة ((0.000) وبناءً على ذلك ينت رفض الفرضية الصفرية، وقبول الفرضية البديلة فيما يتعلق بجميع انواع الهدر. 2- اختبارالفرضية الفرعية الأولى: لا يوجد أثرذودلالة إحصائية عند مستوى دلالة (

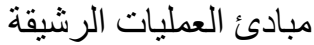
جدول (6) نتائج تحليل الانحدار الخطي البسيط للتالف في مبادئ التصنيع الرشيق

\begin{tabular}{|c|c|c|c|c|c|c|}
\hline دلالةتوى & المحسوبة & Beta & التحديدم2 معلمل & B & المتغير التابع & المتضير المستقل \\
\hline 0.000 & 19.02 & 0.77 & 0.50 & 7.61 & مبادئ التصنيع & التالف \\
\hline
\end{tabular}

يكون الأثر ذيدلالة إحصائية عند مستوى معنوية (

Spss v16 المصدر : من اعداد الباحث بالاعتماد على مخرجئ

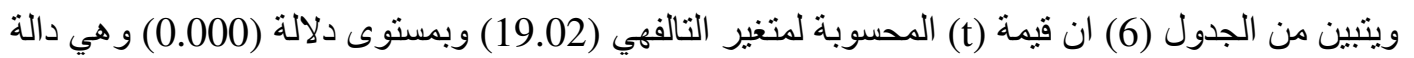

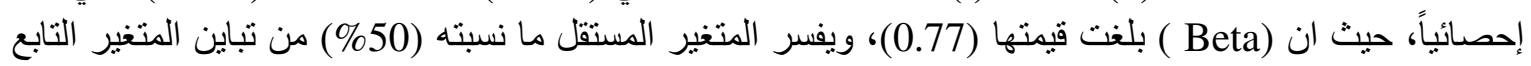

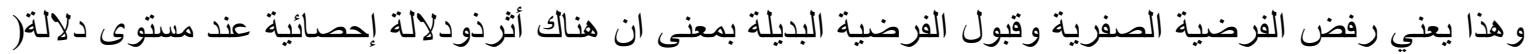
( $\alpha=0.05$ 3-اختبارالفرضية الفرعية الثانية : لا يوجد أثرذودلالة إحصائية عند مستوى دلالة (

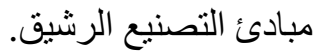




\begin{tabular}{|c|c|c|c|c|c|c|}
\hline دلالةتوى & Tقيمة & Beta & $\begin{array}{c}\text { التحديدمامل Re } \\
\text { R2 }\end{array}$ & B & المتغير التابع & المتغير المستقل \\
\hline 0.000 & 18.09 & 0.59 & 0.53 & 7.61 & مبادئالتصنيع & $\begin{array}{c}\text { تحميل النظام فوق } \\
\text { Muri }\end{array}$ \\
\hline
\end{tabular}

يكون الأثُرذي دلالة إحصائية عند مسنوى معنوية (

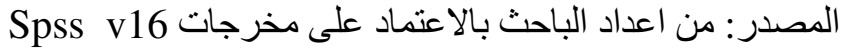

ويتبين من الجدول (7) ان قيمة (t) المحسوبة لمتغير فوق الطاقة هي (18.09) وبمستوى دلالة (0.000)

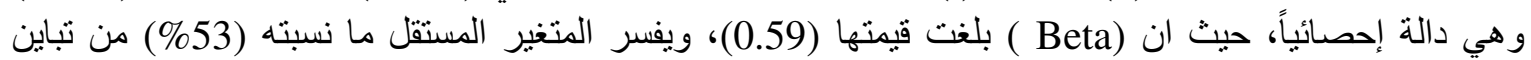
المتغير التابع و هذا يعني رفض الفرضية الصفرية وقبول الفرضية البديلة بمعنى ان هنالك أثرذودلالة إحصائية عند مستوى دلالة ( 1 ( ) لتحميل النظام فوق طاقته في مبادئ التصنيع الرشيق.

3- اختبارالفرضية الفرعية الثالثة: لا يوجد أثرذودلالة إحصائية عند مستوى دلالة(

فيمبادئ التصنيع الرشيق.

جدول (8) نتائج تحليل الاتحدار الخطي البسيط لعدم التوازن فيمبادئالتصنيع الرشيق

\begin{tabular}{|c|c|c|c|c|c|c|}
\hline دلالةتوى & قالمسمة Tية & Beta & 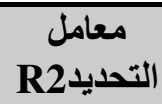 & B & المتغير التابع & المتغير المستقل \\
\hline 0.000 & 1). 04 & 0.57 & 0.51 & 5.13 & الرشيقئلتصنيع & عدم التوازن \\
\hline
\end{tabular}

يكون الأثرذي دلالة إحصائية عند مستوى معنوية (

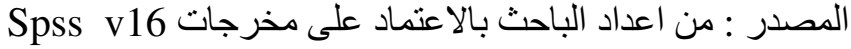

ويتبين من الجدول (8) ان قيمة (t) المحسوبة لمتغير عدم التوازنهي (19.04) وبمستوى دلالة (0.000)

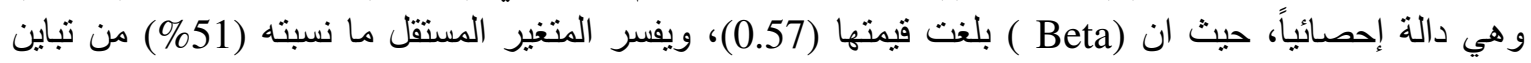

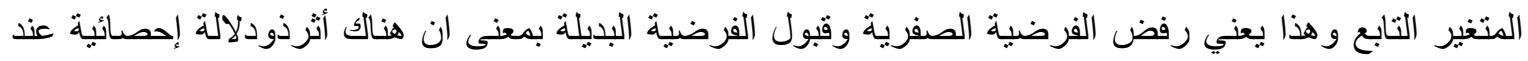
مستوى دلالة)

ثالثا :النتائج :

1.أنشارت النتائج إلى أنُبعد التالف(Muda ) قد احتل المرتبة الأولى بالأهمية بين ابعاد المتغير المستقل (انواع الهدر)

$$
\text { وبمتوسط حسابي مقداره(4.09). }
$$

2. أثنارت النتائج إلى أنُبعد الكمال قد احتل المرتبة الأولى بالأهمية بين ابعاد المتغير التابع مبادئ

التصنيعالرشيقوبمتوسط حسابي مقداره ( 4.01).

3. أظهرت النتائج وجود اثر ذو دلالة احصائية لأنواع الهدر فيمبادئ التصنيع الرشيق. 
إذ كان الثأثير دال من الناحية الإحصائية، وذلك لأن قيم مستويات الدالة جميعها و المر افقة لقيمة f البالغة (52.1) هي أقل من (0.05)، مما يعني وجود أثر لأنواع الهدر في مبادئ التصنيع الرشيق. 4. أظهرت النتائج وجود اثر للتالف في مبادئلتصنيع الرشيق حيث قيمة (t) المحسوبة لمتغير التالفهي (19.02) وبمستوى دلالة (0.000) وهي دالة إحصائياً، حيث ان (Beta ) بلغت قيمتها (0.77)، ويفسر المتغير المستقل ما نسبته (50\%) من تباين المتغير التابع .

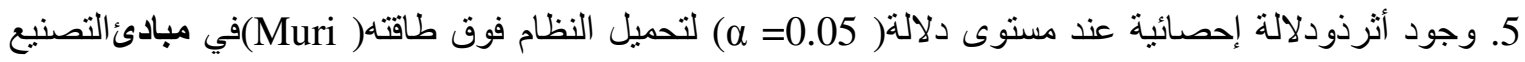
الرشيقحيث بلغت قيمة (t) المحسوبة لمتغير فوق الطاقة هي (18.09) وبمستوى دلالة (0.000) وهي دالة إحصائياً، حيث ان (Beta ) بلغت قيمتها (0.59)، ويفسر المتغير المستقل ما نسبته (53\%) من تباين المتغير التنابع .

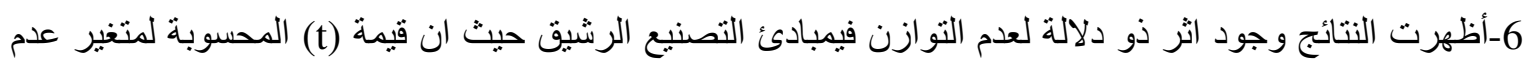

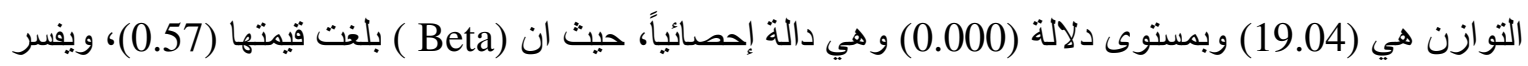
المتغير المستقل ما نسبته (51\%) من تباين المتغير التابع ـ ولهي

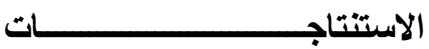

إضافة الى النتائج التي أظهر ها البحث في الجانب العملي، يمكن أن ندرج في ادناه بعض الاستنتاجات:-

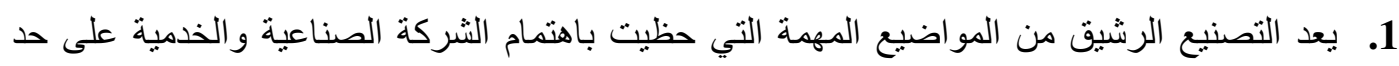
سو اء، كونها تمثل أحد أهم نظم الإنتاج، وتعددت مبادئه و عناصره من خلال تعدد وجهات النظر حوله و التي يعتمد عليها نظام التصنيع الرشيق . 2. تهتم الثركات الصناعية بالعمل من أجل التخلص من الهدر بأنواعه المختلفة كون ذلك يؤدي الى لى تخفيض كلف الانتاج وبالتالي زيادة الأرباح. 3. التخلص من الهدر أو تقليصه يؤدي الى ارتفاع التصنيع الرشيق و هذه العمليات تهدف بشكل أساسي الى

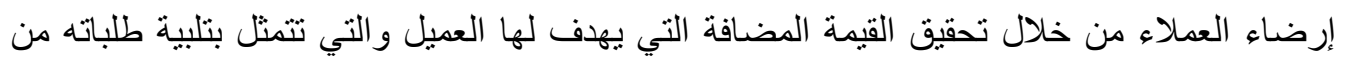
السلع بالكم و الجودة المطلوبة وبالوقت و المكان المحددين. 4. تم تحديد أنواع الهدر الثناث ( Mura \& Muri \&Muda ) واعتبرت من الأنواع المعروفة ، بعدها تم اكتشاف عدد ليس بالقليل من الأنواع الأخرى حديثاً تتمثل بإضاعة الوقت وعدم تتميه المبدعين

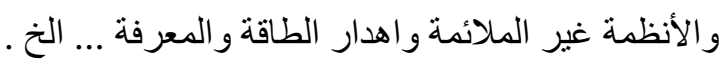

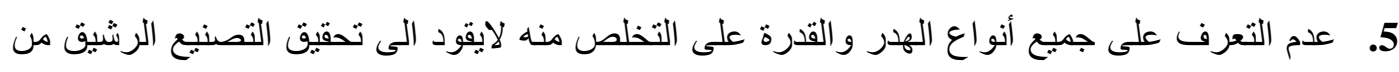

خلال مبادئه الرئيسية. 6. ل ا زال التصنيع الرشيق لم يتحقق بالثكل المطلوب بالرغم من محاولة الثركات الصناعية الاقتداء

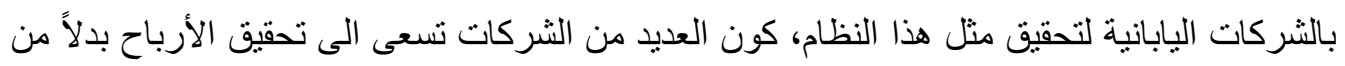




$$
\text { تأسيساً على النتائج و الاستنتاجات التي تم التو اصل اليها، يوصي الباحث بما يأتي:- }
$$

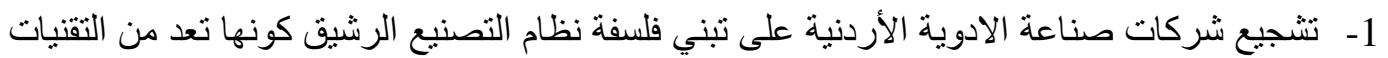

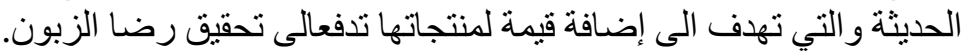

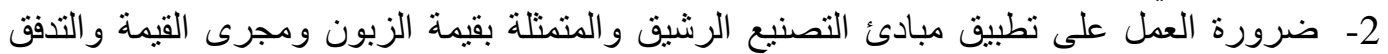

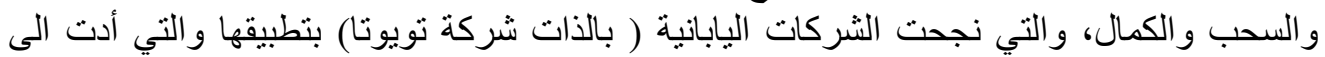
ارتقائها وتقدمها على اقر انها من الثران الثركات المنافسة.

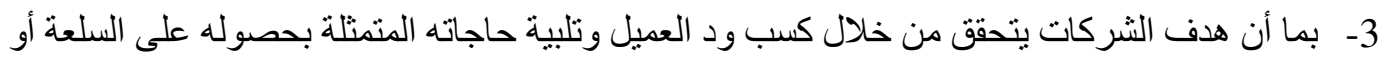

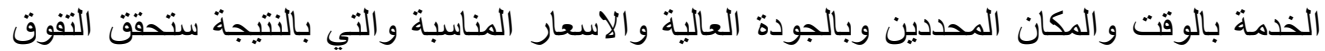

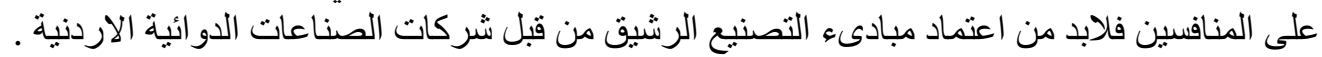

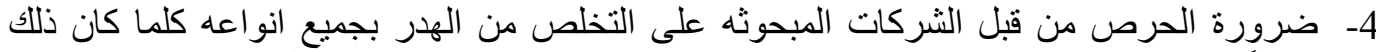

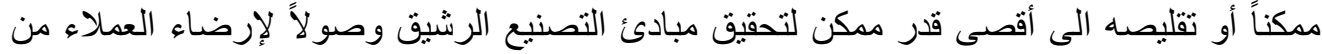

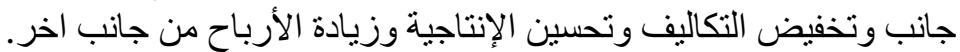

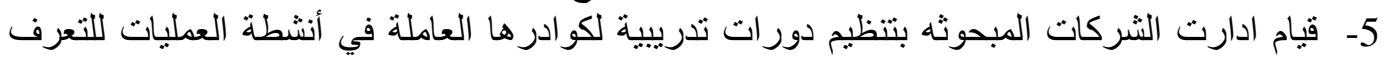
بدقة على أنظمة Lean Manufacturing و JIT \& TPS ومواكبة التطورات التطات الحاصلة عليها وتطبيقها بشكل جيد وناجح في الثركات، ويفضل ان تنفذ تلك الدورات في الثركات اليابانية التي طبقت تلك الأنظمة. 6- توفير منطلبات نظام التصنيع الرشيق والمتمنلة بالكوادر البشرية والمستلزمات المبات المادية والفنية و المعلوماتية كي تكون الثركات المبحوثه قادرة على تنفيذ النظام بنجاح وبالتالتي التفوق على التى الثركات 7- توعية العاملين في الثركات المبحوثه بأهمية تلبية العملاء و الحرص على كسبهم من خلال تقديم

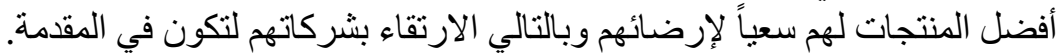

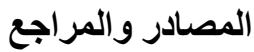

او لا :المصادر العربية:

1- الكتبي ، جميل ، محاضر ات مسجلة عن العمليات الرشيقة. watch?v=IUTtEix2NOK\&feature=share//www.youtube.com//https

2- النعمه ، معتصم هو د محمد، 2006" دور راس المال الفكري في إمكانية إقامة مرتكز ات العمليات

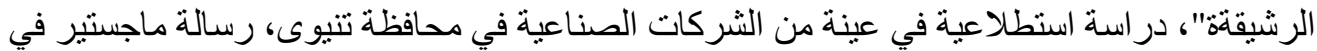

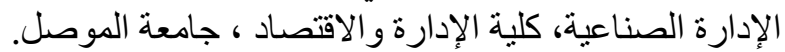
3- محسن ، عبد الكريم و النجار، صباح ، " إدارة الإنتاج و العمليات"، ط4 ، الذاكرة للنشر و التوزيع، 2012.

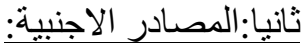

1- Buggy,J \& Nelson.J, Applying Lean production in Mealthcare Facilities, http://www.Informedesing. Umn.edut news,2005. Pdfm .

2- Gopalakrishanan. N. ." Simplified Lean manufacture elements, Rules, tools, and implementation, New Delhi , 2010. 
3- Heizer.J,Render.B and Munson.c , “Opertions Management Sustainability and supply Chain Management" 12th edition,2015.

4- Krajewski. L.j, Ritzam.L.P,andMolhotra.M.K,"operations management processes and supply chains," $10^{\text {th }}$ edition,2013.5- Lonnie Wilson, “ How to implement lean Manufacturing, Mc Graw-Hill ,2010.

6-Russel. R.S \&Taylor B," Operations Management" $9^{\text {th }}$ edition, prentice Hall New Jersey, 2011.

7- Slack . N . \& others, “ Operations Management,” $4^{\text {th }}$ edition, prentice- Hell, 2004.

8-Stevenson W.J “ operation Management,11th edition, Mc Grow Hill, 2012.

9-Turban, E \& others “ Decision Support and business intelligence systems, 9th edition, pearson, New Jersey, 2011.

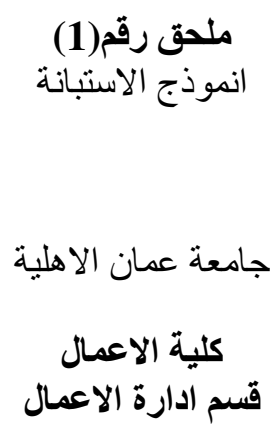

يهدف هذا البحث إلبالتعرف على اثر انواع الهدر ومدى ناثير ها في عملية دعم مبادىء التصنيع الرشيق.و لأهمية رأيكم

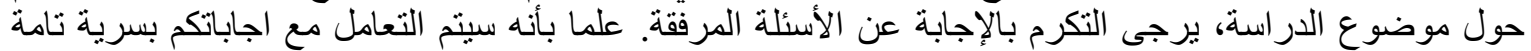
و ولأغر اض البحث البع العلمي فقط. وشكر التعاو نكم البحم 
The Scientific Journal of Cihan University - Sulaimanyia ISSN 2520-7377 (Online), ISSN 2520-5102 (Print)

DOI: http://dx.doi.org/10.25098/1.3.1
Vol. (1) Issue (3) PP: 03-22

May/2017

القسم الأول: البيانات الثخصية :
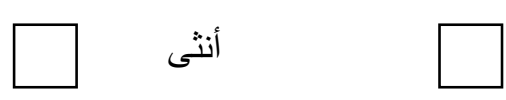

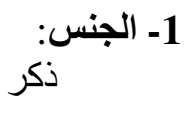

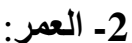

من 31-36 سنة

من 43- 48-48 سنة

أكثر من 55 سنة

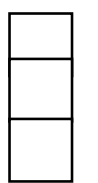

25- اقل من 30سنة

37-37-37-32 سنة

من49- 54 سنة

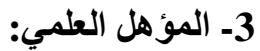

ماجستير

$\square$

ثنانوية عامة دبلوم متوسط بكالوريوس

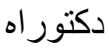

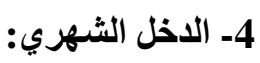

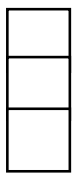

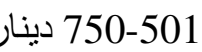

1001

أكثر من 1500 دينار

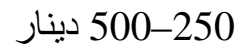

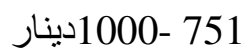

1500-1251

6- الوظيفة الحالية: تُذكر لطفاً.

7- سنوات الخبرة في الوظيفة الحالية:

\begin{tabular}{|l}
$\square$-11 -6 سنو اتة 14 \\
\hline سنة 14
\end{tabular}

- 1 - 3 سنوات ات ات

15 -10 سنة 1 سنة

15 سنة فأكثر 
The Scientific Journal of Cihan University - Sulaimanyia ISSN 2520-7377 (Online), ISSN 2520-5102 (Print)

DOI: http://dx.doi.org/10.25098/1.3.1
Vol. (1) Issue (3)

PP: 03-22

May/2017

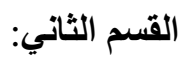

يرجى قراءة العبار ات التالية وبيان ر أيكم فيها وذلك بوضع إثارة (ل ) إز اء الجواب الذي تر اه مناسبا.

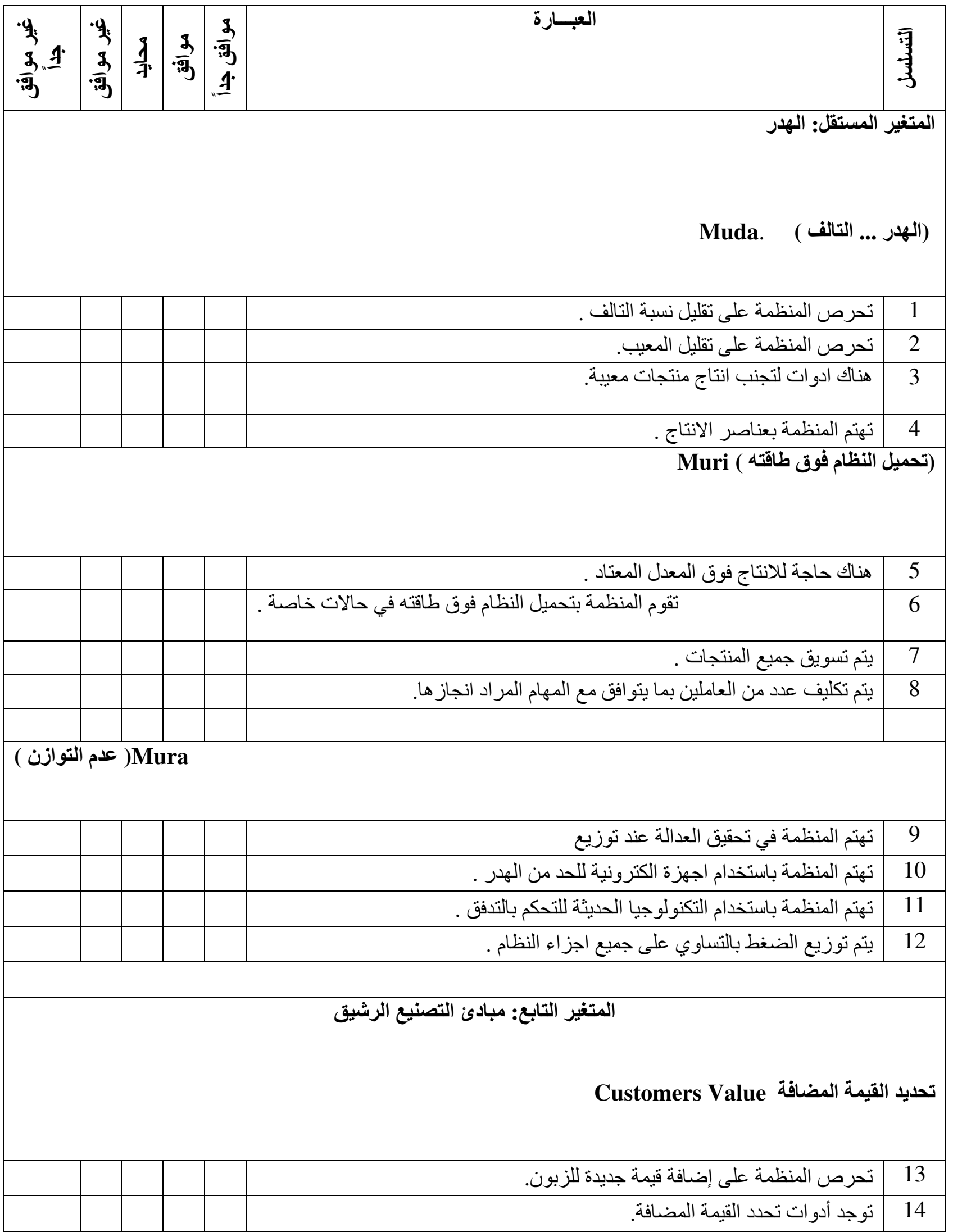


The Scientific Journal of Cihan University - Sulaimanyia ISSN 2520-7377 (Online), ISSN 2520-5102 (Print)

DOI: http://dx.doi.org/10.25098/1.3.1
Vol. (1) Issue (3)

PP: 03-22

May/2017

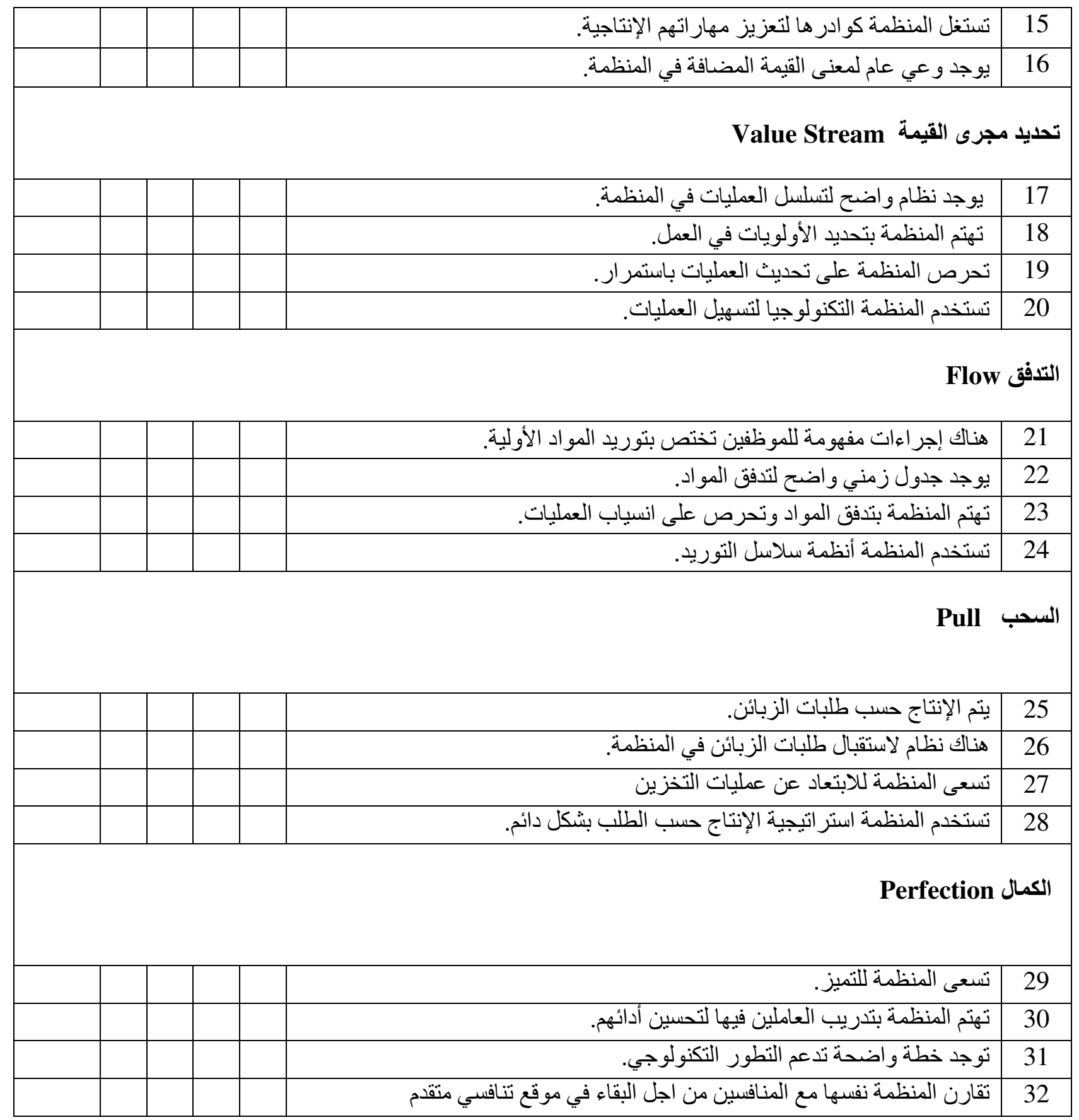

